\title{
Uniformidade e Diversidade no Ensino da Física Básica: os Cursos de Física para Biologia, Desenho Industrial e Farmácia
}

Uniformity and diversity on the Basic Physics teaching the Physics courses for Biology, Industrial Design and Pharmacy

\author{
L.F.S. Coelho \\ Instituto de Física, UFRJ, Cx. Postal 68528, Rio de Janeiro, 21945-970, RJ, Brazil
}

Recebido em 2 de outubro, 2001. Aceito em 4 de março, 2002.

\begin{abstract}
O ensino universitário de Física atinge uma ampla faixa de carreiras. Ele é tradicionalmente dicotômico: enquanto carreiras na área técnico-científica recebem um ensino uniformizado em quatro semestres e com encadeamento formal baseado no Cálculo, as das áreas biomédica e da interface técnico-humana recebem um ensino diversificado por carreira e durando um ou dois semestres. Diversos fatores alteram este quadro, em particular o crescimento mundialmente intenso de áreas como a Genética, a Ecologia, a Farmácia e a Informática. No Brasil, temos também a tendência centrífuga no ensino uniformizado da área técnico-científica. Entre os argumentos para esse esvaziamento do curso unificado, respectivamente levantados pelas unidades de origem dos alunos e pelas de Física, estão a diversidade das necessidades futuras dos alunos e a heterogeneidade da sua formação prévia. O estudo do resultado na prova de Física dos alunos classificados no Vestibular da UFRJ para o período 1994-1997 evidencia que a heterogeneidade é enorme para o conjunto de carreiras, mas que é muito menor quando focamos apenas a Engenharia. Portanto, ambas as explicações para os problemas destes cursos de Física são muito parciais e este estudo da heterogeneidade sugere que causas mais fundamentais estão em ação: a formação prévia dos estudantes, o currículo universitário (carga horária e conteúdo das disciplinas) e o vestibular são inadequados. Numa segunda parte deste trabalho, são apresentadas três experiências na UFRJ de disciplinas de Física para áreas não-técnico-científicas: Biologia, Desenho Industrial e Farmácia. Em resumo, estas disciplinas têm forte conteúdo fenomenológico e qualitativo e são apoiadas em exemplos físicos relevantes para cada área. Isso, em geral, requer tanto um percentual de Física Moderna superior ao usual nos cursos para as áreas técnico-científicas quanto a constante atualização desses exemplos usando-se a Internet. Estas experiências, à parte seu valor intrínseco, fornecem elementos para repensarmos nosso ensino de Física universitária básica.
\end{abstract}

University Physics teaching reaches a wide range of careers, being traditionally dichotomic. In short, careers in the technical-scientific group receive an uniform Calculus-based 4-semester teaching while the ones in the biomedical and technical-human interface areas have with 1- or 2-semester career-diversified courses. Several factors, here analyzed, modify this picture, in particular the growth of areas such as Genetics, Ecology, Pharmacy and Computing, outside the more traditional technical-scientific group and the centrifugal drive of this group, with careers opting to leave the uniform teaching. Among the causes invoked for this migration from the unified course, frequently raised by the students' schools and by the Physics schools, one has the distinct requirements of the several professional options and the heterogeneity of the Physics previous knowledge of the students. The study of the grades obtained in the Physics admission exam for UFRJ in the 19941997 period shows that the heterogeneity is very large, when considering all careers, but is shallow when focusing only on the Enginnering options. Thereby both emphasis for the shortcomings of these Physics courses provide very incomplete answers and this study suggests that more basic causes are at work: previous formation of the students, the univerity curricula (amount of lecture hours and course contents) and the entrance selection process are inadequate. In a second part of this work we present in detail three didatical experiments in UFRJ for "non-technical-scientific" areas: Biology, Industrial Design and Pharmacy. In short, these courses have strong phenomenological and qualitative contents and widely use physical examples of interest for each area. This generally requires both a Modern Physics percentage larger than the one for the thechnical-scientific course and a frequent updating of these examples using Internet. These experiments, besides their intrinsic value, give elements for rethinking our teaching of basic University Physics. 


\section{Introdução}

"Onde está a Vida que perdemos
vivendo?/Onde está a Sabedoria que
perdemos no Conhecimento?/Onde está
o Conhecimento que perdemos na In-
formaçâa?"(T.S.Eliot, poeta e PhD em
Filosofia, americano naturalizado inglês).

O ensino de Ciências Básicas na universidade brasileira vem sendo ministrado por pesquisadores desde a lei 5540 de 1968, a qual implantou o Ciclo Básico (CB). Este tem três objetivos definidos por lei: (a) sanar as deficiências do ensino do segundo grau, (b) auxiliar a orientação profissional do aluno e (c) dar base para as disciplinas do Ciclo Profissional do curso escolhido. Duas tentativas prévias tinham ocorrido na década de 30, a FFCL/USP e a UDF, mas esbarraram na oposição das então chamadas escolas profissionalizantes e não prosperaram [1].

No cômputo geral, a implantação desse ensino hoje pode ser considerada bem sucedida: ela permitiu a revitalização dos currículos, oferecendo uma formação científica mais sólida. Com isso, ela permitiu também (a) a organização de grupos de pesquisa básica, cujos membros ministram os cursos científicos básicos, e assim acarretou a existência de, por exemplo, Institutos de Física com o porte dos atuais e (b) tornou a Pesquisa uma parte essencial da Universidade brasileira.

No caso da Física seu aprendizado é importante para carreiras técnico-científicas (Engenharia, Matemática, Informática, Estatística, Física, Química, Astronomia e as Ciências da Terra), biomédicas (Medicina, Biologia, Biomedicina e Farmácia) e da interface técnico-humana (Desenho Industrial e Arquitetura). Tradicionalmente há um quadro dicotômico: enquanto o primeiro grupo recebe um ensino uniformizado em quatro semestres, com encadeamento formal baseado no Cálculo, os outros dois recebem um ensino diversificado por carreira e durando um ou dois semestres. Suas cargas horárias totais estão respectivamente nas faixas 360-480 e 60-120 horas. Além da flexibilidade administrativa que, entre outras coisas, permite o adiamento da opção profissional, o curso básico unificado também permitiu a homogeneização de disciplinas oferecidas por equipes docentes que, décadas atrás, eram muito heterogêneas.

Há dois enfoques para analisar as disciplinas do Ciclo Básico, averiguando até que ponto atingem os seus objetivos, identificando problemas e propondo soluções $[2]$.

Num primeiro enfoque, devemos olhar para as disciplinas cursadas pelos nossos alunos de bacharelado e licenciatura de Física durante o CB, tanto as nossas disciplinas quanto as oferecidas por outras unidades. Este enfoque é muito importante pois os anos iniciais permitem aos alunos que serão os físicos do futuro se interessarem por Física e terem uma boa formação geral.
Essas disciplinas ocupam metade do tempo acadêmico de nossos alunos de graduação mas a sua importância é maior do que isto, pois, além do seu papel de cartão de visita do IF, concentram quase toda a informação fenomenológica que o aluno recebe durante o curso e introduzem as diversas teorias básicas da Física. Entre as suas falhas, que discutimos, está a quase inexistente discussão de fenômenos não imediatamente explicáveis por teorias clássicas. Assim, o Magnetismo e a condução elétrica em meios materiais, o calor específico de gases diatômicos e de sólidos, a tensão superficial e a capilaridade, as vibrações em sólidos e em moléculas, a interação da radiação eletromagnética solar com gases e com sólidos, todos estes e muito outros pontos, quer estejam explícitos nas ementas (como alguns estão) quer contidos em qualquer bom livro-texto, recebem em geral pouca ou nenhuma ênfase. A má formação nestas áreas certamente dificulta a opção posterior do aluno pela pesquisa experimental em Física.

Além disso, este primeiro enfoque permite que, ao nos posicionarmos como "usuários" ou na linguagem de Qualidade Total como "clientes", vejamos os méritos e as falhas das disciplinas de Física que oferecemos aos nossos próprios alunos e, a partir disso, analisemos as que oferecemos a outras unidades. No entanto a falta de distanciamento de nosso próprio currículo dificulta este método direto e não o seguiremos neste trabalho.

No segundo enfoque, o reverso, podemos discutir as disciplinas básicas de Física oferecidas aos alunos da Universidade em geral. No caso específico da UFRJ, estaremos assim avaliando uma tarefa que envolve $60 \%$ do nosso corpo docente, outras universidades devendo apresentar percentuais similares. A possível inserção dessas disciplinas em realidades muito diversas (no caso da UFRJ, por exemplo, disciplinas de Física são oferecidas para mais de 20 opções profissionais distintas) torna essa análise bastante difícil e, freqüentemente, leva a estereótipos do que, digamos, engenheiros navais, farmacêuticos industriais, ecólogos, ou programadores visuais precisam saber de Física.

Essa análise usando o segundo enfoque, é a efetuada neste artigo. Ela permite não apenas termos disciplinas mais integradas à formação desses profissionais como também uma maior compreensão das disciplinas básicas que ministramos aos nossos próprios alunos de Bacharelado e Literatura em Física. Na UFRJ temos a chamada evidência anedótica dessas falhas no exame de ingresso na Pós-Graduação em Física, quando as questões de nota mais baixa são as de Física Básica.

Neste trabalho, primeiramente discutimos o esgotamento deste modelo, talvez mais evidente na tensão entre as disciplinas unificadas da área técnico-científica e o crescente detalhamento das opções no vestibular para essa área. No caso da UFRJ, por exemplo, a Geografia, a Farmácia, a Geologia, a Atuária, a Química Industrial e a Informática optaram, ao longo de três décadas, ou por disciplinas do segundo tipo ou pela continuação no 
curso unificado mas com o corte de disciplinas. Ainda no caso da UFRJ, a Engenharia se afastou recentemente durante alguns semestres voltando após ter garantido disciplinas menos centralizadas. Em anexo, apresentamos os resultados na prova de Física no Vestibular da UFRJ (1994-1997), que evidenciam a diversidade de resultados por carreira.

Na segunda parte analisamos o ensino básico de Física fora da área técnico-científica. É dada ênfase à experiência das disciplinas de física para três cursos: Biologia, Desenho Industrial e Farmácia. Em anexo apresentamos as ementas dessas disciplinas. Finalmente são apresentadas as conclusões.

\section{O esgotamento do modelo}

Se eu pudesse escolher entre uma pretensa universidade sem regime de internato e sem supervisão de orientadores, a qual concederia seus diplomas a toda pessoa aprovada em um exame sobre matérias variadissimas, e uma universidade sem professores, sem exames, que se contentasse em fazer coabitar jovens, durante três ou quatro anos, antes de sua partida para a vida ... eu preferiria sem hesitação a universidade que nãa fizesse nada àquela que exigisse de seus estudantes o conhecimento de todas as ciências existentes.(The Idea of a University, Cardeal Newman, o grande reformador da universidade inglêsa; texto escrito em 1852 e citado em "Concepcões de Universidade", Drèze e Debelle, UFC, 1983).

O presente modelo de Física Básica e de Ciclo Básico está esgotado, em parte pelo seu próprio sucesso, e tem dificuldades em responder a novos desafios. A Universidade Brasileira hoje é muito diferente do que era 30 anos atrás, tendo hoje núcleos de excelência em pesquisa espalhados em todas as áreas (em 2000 se publicaram tantos artigos no Brasil quanto em toda a década de 70) [3]. A qualificação docente é muito mais elevada e homogênea e a infraestrutura didática (computadores, laboratórios e bibliotecas), embora ainda irregular, é muito melhor do que era. As dificuldades no gerenciamento das disciplinas básicas de forma satisfatória para todas as unidades envolvidas são em parte associadas aos desconhecimentos mútuos desses crescentes recursos humanos e materiais.

Outro problema é o crescente detalhamento da opção profissional no vestibular, o que torna inaplicável o objetivo de orientação vocacional e permite que os alunos ingressantes em opções distintas tenham rendimentos acadêmicos muito distintos (ver Anexo A). Geram-se assim necessidades de revisão do Primeiro e do Segundo Graus também muito distintas, e isso produz tensões nas disciplinas unificadas.

Há outras razões desse esgotamento que transcendem o Brasil. Primeiramente, as demandas que outras áreas do conhecimento fazem à Física são muito distintas das de 30 anos atrás, quando algumas dessas áreas nem existiam, mas faltam mecanismos eficientes que as transmitam de uma unidade para outra. A existência de computadores, calculando ou simulando resultados, também alterou essas demandas: um micro comum hoje supera em muito o poder de cálculo do mais poderoso computador "main-frame" da IBM de 30 anos atrás. O quadro da formação necessária para cada um dos "clientes" da Física tem mudado muito nas últimas décadas, em parte graças a essa crescente disponibilidade de recursos computacionais e que permitiu o também crescente uso de descrições quantitativas de fenômenos.

O grupo de profissões técnico-científicas, que precisa de uma visão quantitativa da Física, instrumentalizou em parte esta necessidade através do uso de programas de computador que trazem embutida a Física, sendo exemplos disto na Engenharia o cálculo de estruturas e o projeto de peças no computador (CAD). As vantagens são evidentes, mas há o risco de termos profissionais que sejam essencialmente usuários de programas crescentemente complexos, desenvolvidos por seus colegas de profissão. Sem entender em que estes programas são baseados, como interpretar os resultados que eles fornecem?

Por outro lado, profissões que precisavam só da visão fenomenológica e qualitativa, cada vez mais, precisam dessa visão quantitativa para, por exemplo, realizar simulações computacionais, calcular problemas inversos e fazer análises estatísticas. O uso, na década de 50, da difração de raios-X para entender a estrutura do DNA foi um divisor de águas. Hoje talvez os maiores usuarios de computadores sejam os geneticistas moleculares, que os empregam para fazer o seqüenciamento do DNA, enquanto a Modelagem Molecular de fármacos e moléculas orgânicas trouxe a Mecânica Quântica para o centro das pesquisas farmacêuticas.

Outra mudança está no dinamismo relativo das diversas áreas. Por exemplo, um estudo recente da National Science Foundation (NSF) mostrou que na última década ocorreram nos Estados Unidos substanciais aumentos da procura por Medicina, Biologia e Computação e também substanciais quedas da demanda por Matemática, Física e Engenharia. Isso sabemos que altera não só o número mas também o perfil acadêmico dos ingressantes em cada opção, exigindo maior ou menor revisão dos conceitos do ensino fundamental. A formação básica em Física continua importante mas necessita-se de livros-texto e de cursos de Física crescentemente diversificados para permitir tanto esta revisão quanto a compreensão de fenômenos, técnicas e métodos físicos em áreas como a Genética, a Meteorologia, a Ecologia ou a Farmácia.

A discussão do esgotamento do presente modelo dual do ensino de Física Básica, assim como das disciplinas específicas, é difícil por duas razões. Primeira- 
mente não há ainda distanciamento crítico, pois o CB foi resultado, em boa parte, da luta da comunidade de Física, e a demanda de ensino de Física para outras unidades é responsável pelo tamanho atual dos Institutos de Física. Em segundo, no mundo todo universidades são instituições conservadoras, e isto não é diferente no Brasil: os currículos e as ementas num certo instante refletem geralmente os recursos humanos e materiais e o estado do conhecimento com atrasos de anos ou mesmo de décadas. Num exemplo deste conservadorismo, as universidades resistem à desregulamentação parcial das profissões liberais, autorizada pela nova Lei de Diretrizes e Bases. O ensino de Física para as áreas não-ténico-científicas é um bom ponto de partida para discutir esse esgotamento.

\section{O ensino básico de Física fora da área técnico-científica}

\begin{abstract}
É suficiente para um psicohistoriador, como tal, saber sua Bioestatistica e sua Neuroquímica eletromatemática. Alguns não sabem mais nada e estão credenciados apenas a serem técnicos estatísticos. Mas um Orador deve ser capaz de discutir o Plano sem Matemática. Senão o Plano em si mesmo, pelo menos a sua filosofia e os seus objetivos. (Segunda Fundação, Isaac Asimov, 1950)
\end{abstract}

Há duas formas usuais de encarar as disciplinas para estas carreiras. A primeira é resumir acriticamente os quatro semestres dos cursos formais, técnico-científicos, tentando manter todo o formalismo, o que os torna inviáveis e inúteis. A segunda é ter apenas uma revisão do Segundo Grau, o que não atende às necessidades dessas áreas. Para evitar este dilema, tanto o conteúdo como a organização destes cursos devem ser repensados.

O conteúdo fenomenológico qualitativo não estava tradicionalmente presente nos textos universitários europeus ou americanos, pois, como já tinha sido visto no Ensino Fundamental, podia posteriormente ser estudado a partir das ferramentas do Cálculo e com linguagem mais quantitativa e formal. A situação brasileira é visivelmente distinta: não apenas o conteúdo fenomenológico qualitativo falha no Primeiro e no Segundo Grau como falham mesmo formalismos elementares como a Álgebra, a Aritmética, a Geometria, a Leitura e a Escrita. O Ensino Fundamental de bom nível, razoavelmente universal na Europa Ocidental e na América do Norte, aqui ocorre apenas em instituições de elite.

Na última década, no chamado Primeiro Mundo, está sendo desenfatizada a discussão formal e incluída a fenomenológica qualitativa. Isso, em parte, corresponde ao já mencionado deslocamento dessa necessidade da
Física e da Matemática para elites profissionais que desenvolvem programas de computador. Por outro lado, corresponde também à dramática queda na procura pelas Ciências Exatas e Tecnológicas. Essas mudanças implicam em que agora corramos o risco de importar disciplinas qualitativas como antes importávamos as formais.

Estas disciplinas para as carreiras chamadas "nãocientíficas" trazem uma lição para as carreiras de Ciências Exatas e Tecnológicas: a estrutura formal é fundamental, mas não é tudo. Essa estrutura formal não é compreendida quando (a) o aluno tem falhas sérias na formação fundamental e (b) quando os exemplos não são motivadores. Os cursos de quatro semestres permitem o desenvolvimento formal - essa é a sua diferença em relação aos primeiros - mas exigem uma visão clara das deficiências prévias dos alunos assim como do uso presente e futuro desse conhecimento. Infelizmente, a estrutura atual da Física Básica para a Engenharia adquiriu uma visão estereotipada das necessidades desta, que afasta a questão de qual conhecimento físico é realmente necessário. Esta visão impede a descrição qualitativa de fenômenos e discute relutantemente fenômenos não-clássicos como o ferromagnetismo, a condução elétrica em metais ou os associados à termodinâmica de gases moleculares.

O ensino nas áreas "não-técnico-científicas" deve ser fortemente voltado para a discussão de fenômenos e de situações onde a Física é relevante para cada área, ainda mais que nas Ciências Exatas e Tecnológicas: há menos tempo e há menos chance de que um conceito seja elucidado numa disciplina posterior. Isso é mais profundo que escolhas de exemplos atualizados, as próprias áreas da Física é que mudam. Enquanto a Física de Superfícies (capilaridade e tensão superficial) e a Nuclear (decaimentos radioativos e radioproteção) são mais importantes para um aluno de Biologia que de Engenharia; certamente o reverso ocorre com o ensino da Mecânica e do Eletromagnetismo.

Como exemplo de cursos já existentes na UFRJ e que tentam escapar desta armadilha, temos os cursos para Biologia e Desenho Industrial. O curso de Física para Farmácia foi reformulado, a pedido da Faculdade de Farmácia, e passou de 2 semestres para 1 com ênfase em aplicações de espectroscopia, atualmente estudadas sem nenhum pré-requisito de Física. A partir da experiência do autor que já ministrou seis vezes a primeira disciplina (Biologia), seis vezes a segunda (Desenho Industrial) e cinco vezes a terceira (Farmácia), são discutidos neste trabalho as ementas e os livros-texto viáveis nestes três cursos.

\section{A. Física para Biologia}

A questão central desta seção é "O que um biólogo precisa saber de Física?", e ela procura respondê-la dentro dos limites de um curso de 60 horas. Esta questão remete a outras, muito complexas, como "O que é o 
trabalho de um biólogo hoje?" ou "O que chamamos de Física?". Devido à imensidão e ao dinamismo dessas duas ciências, quaisquer respostas a essas três perguntas, inclusive as que são dadas neste texto ou nas aulas deste curso, serão sempre provisórias e parciais, nos diversos sentidos da palavra. Nas referências [4-7] apresentamos alguns livros-textos para esta disciplina, com breves comentários.

Para alguns o trabalho do biólogo é a aventurosa coleta de espécimens e seu estudo posterior, como numerosos biólogos fizeram e ainda fazem. Um dos muitos exemplos, mas talvez o mais relevante para a Biologia, é a famosa viagem de Charles Darwin durante a qual visitou o Recôncavo baiano, o Rio de Janeiro, o pampa argentino, a Terra do Fogo, as ilhas Galápagos e a Oceania. No diário de sua viagem, "Viagem de um naturalista ao redor do mundo", são descritas essas atividades de coleta assim como a barbárie da escravidão no Brasil e o extermínio sistemático dos índios na Argentina, que certamente impressionariam Darwin mesmo que não tivesse os 23 anos incompletos com que começou a viagem. Darwin coletou amostras geológicas e biológicas nessa viagem que durou quase três anos e depois, um pouco com os seus conhecimentos de Geologia e Biologia e muito com a sua capacidade observação e análise, lhe foi possível propor a "Teoria da Evolução" em seu livro "A origem das espécies".

Certamente, ainda é essencial a um cientista, hoje em dia, ter essas qualidades - coletar dados da forma mais completa possível, selecionar os fatos experimentais relevantes entre muitos outros e com eles propor modelos - mas a situação mudou muito no que se refere ao apoio prestado por outras ciências. Darwin não tinha meios de saber a idade de suas amostras, de saber como se transmitiam as características hereditárias ou de saber se as taxas de mutações eram compatíveis com a diversidade de espécies. As outras ciências da época, inclusive a Física, pouco o podiam ajudar, o que certamente dificultou a proposição da Teoria da Evolução.

Situações assim foram cada vez menos comuns, com a Biologia adquirindo independência dentro da Filosofia Natural (Darwin era naturalista) e crescendo fantasticamente. Para isto a Biologia usou os seus próprios métodos e, crescentemente, as técnicas e os conceitos de outras ciências, sendo inúmeros os exemplos deste crescimento interligado. Temos, assim, a descoberta da existência do gene e o seu estudo pelas Genéticas Mendeliana e Molecular, o que envolve o uso intenso da Estatística, da Física e da Química. Temos a Ecologia necessitando da Matemática para as equações diferenciais de Lotka-Volterra, que regem os tamanhos das populações e descrevem como são afetadas pelas condições externas. Finalmente, temos a Biologia Experimental em geral, com o uso intenso de aparelhos e técnicas experimentais originados na Física, na Engenharia e na Química.

O crescimento da Biologia se deu principalmente nessas áreas integradoras - a Genética, a Ecologia, a Bioquímica e a Biofísica - mas também ocorreu nas numerosas áreas específicas, como a Botânica, a Zoologia e a Microbiologia. Em suma, para saber a resposta à questão "O que um biólogo precisa saber de Física?", é preciso lembrar desta diversidade.

A Física estuda os sistemas mais simples existentes na Natureza, aos quais consegue aplicar modelos qualitativos e quantitativos, introduzindo conceitos como "partícula", "onda", "massa" e "carga elétrica" e procura matematizar este processo de análise, o que lhe permite fazer previsões quantitativas. O equilíbrio entre os conceitos e as fórmulas é essencial, e isso pode ser visto em qualquer área da Física. Por exemplo, numerosos fenômenos na Física são ondulatórios, como o som, a luz ou a vibração de uma membrana, o que torna necessário saber o que é uma onda e estudar as características que a definem, mas não é tão importante assim saber as fórmulas das velocidades das ondas em cada caso, a não ser que tenhamos um problema específico. O uso da Matemática permeia todo este curso, sendo certamente para muitos alunos uma dificuldade, pois a Física usa mais a linguagem e o raciocínio matemáticos que outras ciências naturais, como a Química e a Biologia. No entanto, o uso da Matemática reflete a maior simplicidade dos objetos de estudo da Física e a existência de um pequeno número de leis básicas, que podem ser todas escritas em meia folha de papel.

A descrição e a compreensão qualitativas dos fenômenos físicos nunca deveriam ser obscurecidas por modelos quantitativos, mas isso é, infelizmente, muito comum no ensino de segundo grau. É este mau uso da Matemática que leva à imagem da Física como um grande conjunto de fórmulas. A Física usa a linguagem matemática, mas, após estabelecer alguns poucos conceitos e ter modelos qualitativos simples. Se isso não tiver acontecido, de nada adiantará resolver muitos problemas de queda livre, de formação de imagens, de calor ou de circuitos elétricos. Dito isso, o abuso eventual da Matemática não nos deve cegar quanto à sua importância essencial na Física e quanto à possibilidade de seu uso em problemas biológicos.

Os problemas físicos da atenuação da luz após atravessar um objeto, da emissão de radiação por um material radioativo e de carga ou descarga de um capacitor são matematicamente similares aos problemas biológicos do crescimento de uma população ou da inserção de material genético em uma célula, todos envolvendo o conceito de exponencial e o de derivada. A conversão de unidades, o uso de escalas logarítmicas em gráficos e a notação exponencial de números muito grandes ou muito pequenos são outros tantos exemplos destas analogias. As aplicações da Física na Biologia e nas suas áreas limítrofes, como a Bioquímica, a Biofísica e a Ecologia matemática, vão do uso de moléculas orgânicas marcadas com átomos radioativos até o uso 
de satélites para o sensoreamento remoto de ecossistemas terrestres. Como essas aplicações abrangem as mais diversas áreas da Física, neste curso fornecemos uma visão panorâmica, a qual será um pouco como a referida nas frases finais do diário de viagem de Darwin. Será necessário parar um pouco em cada lugar, aproveitando o melhor possível o tempo e tentando evitar o risco da superficialidade...

\section{B. Física para Desenho Industrial}

Quando o Departamento de Desenho Industrial (DI) solicitou a criação desta disciplina, ele desejava que ela cobrisse as áreas: Mecânica, Acústica, Termologia, Eletricidade e Ótica. Depois de várias reuniões com os professores responsáveis pela coordenação das duas especialidades de DI - Projeto de Produto (PP) e Programação Visual (PV) -, ficou claro que os requisitos de cada especialidade eram muito distintos. Enquanto a primeira especialidade (PP) se interessava por todas as áreas acima e exigia o maior número de exemplos práticos em que objetos teriam discutido seu funcionamento, para a área de Programação Visual apenas a Ótica era fundamental.

Assim sendo, a disciplina "Física" revê as diversas áreas da Física vistas no Segundo grau e introduz algumas outras. As áreas revistas são a Mecânica, subdividida em mecânica de partículas e de corpos rígidos, Acústica, Termodinâmica e Mecânica dos fluidos, e o Eletromagnetismo, por sua vez dividido em eletricidade, magnetismo e ótica. Os temas adicionais são as propriedades mecânicas, térmicas, elétricas e óticas dos diversos materiais e as propriedades de partícula da luz. Assim, por exemplo, o efeito Joule é essencial para discutir as características de uma luminária ou a parte externa de qualquer aparelho elétrico, que necessita ser apropriada à dissipação do calor nele gerado. Da mesma maneira, sem falar um pouco em átomo não é possível falar sobre as propriedades dos diversos tipos de lâmpadas (apenas pode-se falar da incandescente, e em especial não se pode falar de laser).

Um tema que também aparenta ser muito ambicioso num curso de 4 horas semanais, "Danos causados em sólidos pela luz solar e por outras radiações", é de interesse imediato pela degradação sofrida por qualquer plástico, inclusive tintas, ou papel quando exposto à luz solar. Nesse caso, o relevante é que os alunos saibam que a radiação UV quebra as moléculas e altera as suas características como refletoras de luz visível.

A geração e a dissipação do calor no corpo humano e as propriedades térmicas dos materiais são temas essenciais para entender desde a escolha de materiais para construir móveis e a dissipação do calor gerado por efeito Joule (um retroprojetor é um exemplo extremo, onde uma lâmpada gera $800 \mathrm{~W}$ ) até o efeito estufa. Em outro exemplo ligando calor, eletromagnetismo e DI, temos o forno de microondas, cujo princípio básico de operação deve ser compreendido pois ele revoluciona todo o projeto de objetos para uso em cozinhas.

No curso de DI, os estudantes discutem bastante os usos de plásticos e de papel, incluindo os problemas de reciclagem. Em particular, aprendem que o uso do isopor deve ser evitado, por ser feito de CFC, o qual parece ser o principal causador do "buraco na camada de ozônio". Embora a compreensão deste fenômeno ainda seja preliminar, pois a alta atmosfera onde se localiza o ozônio apenas agora está sendo estudada, a discussão deste assunto na disciplina Física não é descabida, em particular uma visão rápida do papel do ozônio na alta atmosfera para bloquear a radiação UV e do porquê de $\mathrm{N}_{2}$ e $\mathrm{O}_{2}$ serem transparentes para a radiação UV.

A mecânica dos fluidos pode também parecer um tema inteiramente deslocado mas é importante em virtude de aerodinâmica dos meios de transporte, como carros e trens, em que vários estudantes realizam projetos. Alguns destes temas (propriedades da atmosfera como absorvedor da luz solar e propriedades térmicas do corpo humano) estão razoavelmente bem explicados no livro "Física para ciências biológicas e biomédicas", de Okuno, Caldas e Chow [5].

É claro que alguns dos estudantes vão estar envolvidos em projetos de mecânica (por exemplo, um carrinho porta-mala em aeroportos ou uma cadeira de rodas auto-elevável) e eles têm que entender conceitos como torque, momento angular e trabalho, mas julgo que não durante metade do curso, como seria se o fosse mantida a proporção atual das 4 Físicas Básicas .

Quanto ao livro-texto, não existe um ideal para esse curso. Um possível é o Física Moderna, de Williams, Metcalfe, Trinklein e Lefler, de dois volumes [8]. Esse livro apresenta os fenômenos físicos sem se prender em demasia a fórmulas e sendo razoavelmente completo. No entanto, mesmo sendo o melhor, é um pouco extenso e lhe faltam exemplos mais modernos de aplicações da física.

Livros de segundo grau podem ser usados, tendo boa parte do conteúdo da disciplina. Em geral possuem os defeitos de excesso de fórmulas, de falta de aplicações realistas da física e de não cobrir toda a matéria da disciplina. Mesmo assim, se utilizados de forma complementar a notas de aula, podem ser úteis.

Uma área muito importasnte para estudantes de Desenho Industrial é o estudo dos sentidos humanos, particularmente a audição e a visão. Esse estudo é essencial não só para as aplicações ergonômicas de um produto novo (como uma cabine telefônica ou uma luminária) mas para a Programação Visual, onde a Teoria da Cor é uma informação básica. Um livro clássico para termos uma introdução a estes tópicos é o de Goldstein [9].

\section{Física para a Farmácia}

Recentemente a Faculdade de Farmácia pediu que a disciplina passasse de 2 para 1 semestre e sugeri- 
ram ementa idêntica à do curso para Biologia, listada abaixo. No entanto julgamos que deve haver uma ênfase maior na Física por trás das técnicas espectroscópicas, pois a única possibilidade de compactar um curso é tê-lo realmente voltado para a realidade de cada área.

Crescentemente a Farmácia se aproxima da Genética Molecular, com todas as suas técnicas experimentais baseadas na Física, e da Química Teórica, com a Dinâmica Molecular de fármacos e o cálculo quântico de estruturas moleculares. A Química Teórica é em grande parte indistinguível da Física Atômica e Molecular.

Além da bibliografia usada no curso de Física para Biologia [4-7], um livro importante é o "Fundamentos de análise instrumental", de O.A. Ohlweiler [10]. Nele, após uma introdução muito sucinta à Física Moderna, é feita uma descrição das diversas técnicas espectroscópicas nela baseadas. Uma análise recente do ensino de Física para Farmácia é dada na referência [11].

\section{Conclusões}

A popa e a proa de nossa didática há de investigar isto, a maneira pela qual os que ensinam ensinem menos e os que aprendem aprendam mais... (Didactica Magna, J.A. Comenius, 1650, traduzido por N.F. AbuMerhy, Editora Rio, 1978)

O comentário acima é o lema do livro pioneiro da ciência da Didática, "Didactica Magna". Ele foi escrito por Comenius que viveu 350 anos atrás numa época tão conturbada por guerras que cerca de um terço da população alemã morreu e até a sua escola na Holanda foi incendiada pouco após sua morte. A frase pode parecer trivial mas é central aos nossos problemas hoje: temos que ensinar cada vez menos horas, com os alunos aprendendo cada vez mais. Em primeiro lugar, como professores universitários, devemos insistir em que a decisão de escolha detalhada da profissão seja feita após cursar alguns semestres. Infelizmente, a maioria das escolas prefere o reverso, opções cada vez mais detalhadas no vestibular, levando a uma heterogeneidade grande entre os alunos e inviabilizando parte dos objetivos do CB técnico-científico. Em segundo lugar, a grande expansão numérica do Primeiro e do Segundo Grau foi acompanhada de uma queda na qualidade da formação, evidente em medidas que vão do nacional ENEM ao internacional PISA.

Assim sendo, os outros dois objetivos da Física Básica - dar a base necessária para as disciplinas dos diversos ciclos profissionais e sanar as deficiências prévias - são cada vez mais importantes. Esses objetivos são centrais para as disciplinas fora da área técnicocientífica.
Em resumo, então, o ensino de Física a essas áreas não-técnico-científicas nos fornece boas indicações de como poderemos ensiná-la de forma mais abrangente. Isto melhorará não apenas o ensino oferecido a essas áreas e à área técnico-científica, o que é uma das funções principais de um Instituto ou Departamento universitário de Física, como melhorará a própria formação dos futuros físicos. Isso certamente é difícil, ainda mais pela pressão para diminuição da carga horária mas, no espírito da frase de Comenius, a eficiência de uma disciplina não pode ser medida por quanto o professor ensinou mas sim por quanto o aluno aprendeu.

\section{Agradecimentos}

Agradeço o apoio financeiro da Fundação Universitária José Bonifácio (FUJB) e da Coordenação de Aperfeiçoamento de Pessoal do Ensino Superior (CAPES) e também a leitura cuidadosa e as sugestões de Fabio Zappa.

\section{Referências}

[1] M.L.A. Fávero, A universidade brasileira em busca de sua identidade, Editora Vozes, 1977. Embora existam numerosos livros com a história da universidade no Brasil este é um livro clássico: compacto e com uma boa revisão bibliográfica.

[2] R. Beichner, L. Bernold, E. Burniston, P. Dail, R. Felder, J. Gastineau, M. Gjertsen e J. Risley, "Case study of the physics component of an integrated curriculum", Am.J.Phys. 67 (1999) S16-S24.

[3] L.F.S. Coelho, "A produção científica no Brasil nos últimos 30 anos: desigualdade regional, diversidade institucional e comparações internacionais", submetido a publicação (2001).

[4] N.C. Hilyard e H.C. Biggin, Physics for applied biologists, Edward Arnold, 1977. Este livro tem 223 páginas, é bastante conciso mas tem numerosos exemplos de interesse biológico. Usa uma ordem quase consensual de tópicos, começando com Mecânica de Partícula e Ondas, passando para a Física Moderna, a Eletricidade, a Óptica, a Termodinâmica, as propriedades térmicas e mecânicas de materiais, e o uso e os cuidados com radiações ionizantes. O maior obstáculo ao seu uso é a inexistência de tradução para o português.

[5] E. Okuno, I.L. Caldas e C. Chow, Física para ciências biológicas e biomédicas, Harper \& Row do Brasil, 1982. Este livro cobre a maior parte da ementa de um curso para Biologia (ou Farmácia), sendo um texto possível. Ele é planejado para um curso de 2 semestres na USP, que engloba estudantes de Biologia e de Medicina. O seu tamanho (490 páginas), a sua ordenação de tópicos, o seu abuso eventual de fórmulas e o seu uso quase exclusivo de exemplos médicos, no entanto, o tornam desaconselhável. Mesmo para aplicações de Física em Medicina esse 
livro está desatualizado (faltam RMN, EEG, ECG e lasers, por exemplo), sendo aconselhável complementálo com a referência 4. Os que usarem este livro deverão fazê-lo fora da ordem usual que ele apresenta (por exemplo, introduzindo a dualidade partícula-onda nas primeiras páginas). Nem os tópicos do livro serão todos vistos no curso, nem toda a ementa do curso está mencionada no livro. Esse livro dever ser complementado pelo caderno de aula de cada um e eventuais apostilas e listas de exercício que serão distribuídas (exemplos representativos dessas listas estão nas páginas http://omnis.if.ufrj.br/ coelho/farmacia.html e http://omnis.if.ufrj.br/ coelho/biologia.html ). O conceito de força é visto no guia de estudos 1.2 (pág. 406 a 408), e os conceitos de energia e de trabalho no capí tulo 9 , onde também é vista a conservação de energia (pág. 82 a 96). (O livro não contém os itens 1.1, 1.2 , e 1.3 do programa.) O conceito de ondas é visto no capítulo 14 (pág. 206 a 219), o som no capítulo 15 (pág. 222 a 235) e as ondas "luminosas" (eletromagnéticas) na seção 1.3 (pág. 2 e 3). As teorias da audição e da visão humanas, cuja bases foram propostas em dois trabalhos clássicos de Helmholtz, não são mencionadas. $\mathrm{O}$ ítem 3.1 do programa corresponde às seções 1.4 e 1.5 (pág.3, 4 e 5) e na seção 4.5 (pág. 33 a 38); a estrutura dos átomos é vista no capítulo 4 (pág. 28 a 33); as radiações são vistas na seção 1.7 (pág. 8,9 e 10) e nos capítulos 5, 6 e 3 (pág. 41 a 46, 49 a 53 e 21 a 26). (Infelizmente só discute a radiação gama, quando a esmagadora maioria das aplicações de radiação em Biologia usam emissores beta.) A eletricidade é vista no capítulo, 21 (pág. 354 a 366); a ótica, nos capítulos 17 e 18 (pág. 251 a 286); a temperatura, na seção 10.3 (pág. 102 a 106); o calor no capítulo 11 (pág. 115 a 122); e a pressão e a hidroestática, nas seções 19.2 a 19.6 (pág. 292 a 303). A dinâmica de fluidos é vista nas seções 20.1 a 20.5 e 20.7 .1 (317 a 334 e 340 a 342 ) mas estranhamente não é usada para discutir o vôo de animais (Guia 2, pág. 421 a 431). A discussão da emissão e da absorção de luz por átomos e moléculas (item 4 do programa), que é fundamental para a análise da composição de amostras, não está nesse livro, assim como a instrumentação elétrica (item 6), sendo uma boa referência o livro Fundamentos de Análise Instrumental, referência 8. Particularmente, o livro não discute instrumentos e técnicas fundamentais para a Biologia como sensores térmicos e centrífugas, ou como o uso e as medidas de radiproteção para emissores-beta.

[6] R.K. Hobbie, "Intermediate Physics for Medicine and Biology", Springer (1997, terceira edição). Livro que exige conhecimento de Cálculo, mas que detalha bastante as aplicações de Física em Medicina (a maior exceção é a Tomografia de Ressonância Magnética Nuclear, o que pode ser atribuído à novidade dessa técnica). Infelizmente, as aplicações em Biologia ganham bem menos ênfase.

[7] J.B. Marion e W.F. Hornyak, "General Physics with Bioscience Essays", Krieger (1985, segunda edição). Ele contém numerosos textos biomédicos. Esses textos recentemente foram traduzidos por M.A.F. Gomes e E.J.R. Parteli em artigo da RBEF 23 (2001) 10, o qual é, essencialmente, a tradução deles.
[8] J.E. Williams, H.C. Metcalfe, R. Trinklein e F.E. Lefler, Física Moderna, dois volumes, Renes (1970). Esse livro apresenta os fenômenos físicos sem se prender em demasia a fórmulas e sendo razoavelmente completo. Por exemplo, fala um pouco da teoria da sensação de cor e da cromaticidade, temas geralmente ignorados em livros de Física Básica. No entanto, é um pouco extenso e lhe faltam exemplos de aplicações da Física Moderna.

[9] E.B. Goldstein, Sensation and Perception, sexta edição, Wadswort, 2001. Excelente introdução à Física, à Química e à Fisiologia dos sentidos externos, particularmente da visão e da audição. É o texto padrão para essa introdução à Ciência dos sentidos e da percepção.

[10] O.A. Ohlweiler, Fundamentos de análise instrumental, Livros Técnicos e Científicos Ed. (1981). Excelente compilação de técnicas espectroscópicas, feita após dar uma revisão de Eletrônica e de Física Moderna.

[11] Corinne A. Manogue, Philip J. Siemens, Janet Tate, Kerry Browne, Margaret L. Niess e Adam J. Wolfer, "The pre-pharmacy major: A survey of physics requirements", Am.J.Phys. 69 (2001) 978-990.

\section{Anexos}

\section{A. A desigualdade das carreiras e o vestibular}

Abaixo são apresentados dados da prova de Física do vestibular da UFRJ, para os anos de 1994 a 1997. Nas tabelas abaixo, o grupo 1 do vestibular corresponde à área biomédica, o grupo 2 à técnico-científica (exceto Geografia) e o grupo 3 é formado, essencialmente, pelo Desenho Industrial e pela Arquitetura, a área técnicohumana. Estes três grupos fazem a mesma prova de Física no vestibular (referida como a prova do dia 3), enquanto as áreas humanas e sociais, que incluem a Pedagogia, fazem outra prova bem mais qualitativa.

O curso de Pedagogia, marcado com *, está mencionado como exemplo das dificuldades da integração na área do ensino de Ciências, pois o seu resultado é dos piores dessa tabela. Os percentuais da terceira e da quarta colunas são calculados em relação ao total, dado na segunda coluna. Estes percentuais indicam o número de alunos que terão dificuldades médias ou pequenas, respectivamente, para acompanhar as disciplinas de Física. Opções profissionais onde estes percentuais são baixos indicam maiores deficiências a sanar vindas da Física do segundo grau. As opções profissionais estão agrupadas por centro e, dentro de cada centro, em ordem decrescente do percentual de alunos que obteve nota igual ou maior que três na prova de Física. Os alunos dos cursos marcados em itálico não têm disciplinas oferecidas pelo IF, embora haja pontos de contato com a Física e haja um rendimento mínimo que indica a viabilidade dessas disciplinas. 
Esses dados mostram que há uma grande diversidade acadêmica nos alunos que atualmente cursam disciplinas de Física, quando se usa um indicador simples e direto como o resultado do aluno que entra na UFRJ na prova de Física do vestibular (ver tabelas abaixo) - Há evidentemente mudanças de ano a ano, com as notas caindo de 94 a 96 e subindo em 97, mas este fenômeno ocorre simultaneamente em todas as opções. A escolha dos indicadores do melhor resultado (nota maior ou igual a 5) e do resultado médio (notas entre 3 e 5) não quer dizer, em hipótese alguma, que os alunos fora destes grupos não terão chance e sim que; provavelmente, terão que realizar um esforço maior e necessitarão ser mais diretamente apoiados nas disciplinas que cursarem.

Há uma enorme diversidade quanto à base prévia em Física de nossos alunos da área tecnológica (CT), agravada por mudança no vestibular da Engenharia que na última década exige escolha detalhada. Esta mudança não justifica, no entanto, índices de reprovação altos na Engenharia pois, embora o percentual de melhores alunos em Física tenha caído (os que tiveram nota 5 no vestibular) manteve-se uma clara maioria de alunos com notas médias e boas (nota 3), exceto nas opções Naval e Metalúrgica. No caso da Engenharia Química, com rendimentos no vestibular abaixo destas duas opções, a unidade tomou a providência de reduzir o número de vagas e abrir o curso de Química Industrial, sendo previsível uma melhora.

Há uma diversidade maior dos nossos alunos da área de Ciências Exatas e da Terra (CCMN) tanto dentro de opções específicas quanto comparando-se resultados médios de opções distintas. Os resultados médios no vestibular dos alunos do CCMN são claramente inferiores aos do CT. Enquanto entra os que se dirigem às opções do Instituto de Matemática (exceto a Licenciatura Noturna) ainda se mantém uma maioria de alunos com médio e bom rendimento, o quadro é diferente para as outras três unidades. Existem cerca de 5 a $20 \%$ de ingressantes com nota igual ou maior que 5,0 enquanto o número de ingressantes com notas médias ou boas varia de 10 a $50 \%$.

Estas tabelas estão em http://omnis.if.ufrj.br/ coelho/catalogo.html, tendo sido parte de um estudo sobre o estado do ensino de Física na UFRJ.

\section{Tabela I}

Resultados da prova de Física do vestibular para candidatos classificados no ano de 1994: Número total de classificados, números com notas $\geq 3$ e 5 , média e desvio-padrão das notas.

\begin{tabular}{cccccc}
\hline Curso & Total & Com nota $\geq 3$ & Com nota $\geq 5$ & Média & Desvio padrão \\
\hline grupos 1+2+3 & 3.093 & $2.320(75 \%)$ & $1.220(39 \%)$ & 4,30 & 1,951 \\
Arquitetura (CLA) & 234 & $192(82,0 \%)$ & $52(22,2 \%)$ & 4,05 & 1,252 \\
Desenho Industrial(CLA) & 98 & $57(58,1 \%)$ & $22(22,4 \%)$ & 3,92 & 1,256 \\
Medicina (CCS) & 192 & $192(100 \%)$ & $187(97,4 \%)$ & 6,94 & 1,151 \\
Odontologia(CCS) & 80 & $80(100 \%)$ & $67(83,8 \%)$ & 5,78 & 1,011 \\
Microbiologia(CCS) & 34 & $31(91,2 \%)$ & $7(20,6 \%)$ & 4,24 & 1,383 \\
Farmácia (CCS) & 141 & $113(80,1 \%)$ & $29(20,6 \%)$ & 3,85 & 1,124 \\
Nutrição(CCS) & 71 & $52(73,2 \%)$ & $6(8,5 \%)$ & 3,55 & 1,240 \\
Biologia (CCS) & 157 & $114(72,6 \%)$ & $24(15,3 \%)$ & 3,71 & 1,253 \\
Bngenharia (CT) & 28 & $17(60,7 \%)$ & $10(35,7 \%)$ & 3,76 & 1,763 \\
Biologia-Modalidade médica (CCS) & 546 & $542(99,3 \%)$ & $419(76,7 \%)$ & 5,91 & 1,445 \\
Mngenharia Química (CT) & 237 & $228(96,2 \%)$ & $141(59,5 \%)$ & 5,36 & 1,463 \\
Matemática (CCMN) & 251 & $228(90,8 \%)$ & $149(59,4 \%)$ & 5,17 & 1,696 \\
Meteorologia (CCMN) & 28 & $14(50 \%)$ & $4(14,3 \%)$ & 3,04 & 1,796 \\
Química (CCMN) & 89 & $53(59,6 \%)$ & $13(14,6 \%)$ & 3,25 & 1,392 \\
Geologia (CCMN) & 49 & $19(38,8 \%)$ & $4(8,2 \%)$ & 2,74 & 1,146 \\
Astronomia (CCMN) & 26 & $9(34,6 \%)$ & $4(15,4 \%)$ & 2,81 & 1,373 \\
Física(CCMN) & 151 & $46(30,4 \%)$ & $26(17,2 \%)$ & 3,62 & 1,677 \\
Pedagogia (CFCH) & 50 & $19(38,0 \%)$ & $4(8,0 \%)$ & 2,81 & 1,050
\end{tabular}


Tabela II

Resultados da prova de Física do vestibular para candidatos classificados no ano de 1995:

Número total de classificados, números com notas $\geq 3$ e 5 , média e desvio-padrão das notas.

\begin{tabular}{|c|c|c|c|c|c|}
\hline Curso & Total & Com nota $\geq 3$ & Com nota $\geq 5$ & Média & Desvio padrão \\
\hline grupos $1+2+3$ & 2.998 & $1.592(53 \%)$ & $646(21,5 \%)$ & 3,77 & 2,100 \\
\hline Arquitetura (CLA) & 240 & $95(39,6 \%)$ & $21(8,8 \%)$ & 2,76 & 1,443 \\
\hline Desenho Industrial Prog.Visual (CLA) & 50 & $30(60,0 \%)$ & $1(2,0 \%)$ & 2,97 & 1,023 \\
\hline Desenho Industrial Proj. Prod. (CLA) & 50 & $13(26,0 \%)$ & $1(2,0 \%)$ & 2,30 & 0,853 \\
\hline Medicina (CCS) & 192 & $190(99,0 \%)$ & $151(78,6 \%)$ & 5,92 & 1,297 \\
\hline Odontologia(CCS) & 80 & $79(98,8 \%)$ & $44(55,0 \%)$ & 5,07 & 1,245 \\
\hline Microbiologia(CCS) & 35 & $14(40,0 \%)$ & $2(5,7 \%)$ & 2,65 & 1,196 \\
\hline Farmácia (CCS) & 144 & $53(36,8 \%)$ & $11(7,6 \%)$ & 2,77 & 1,306 \\
\hline Nutrição(CCS) & 72 & $9(12,5 \%)$ & $1(1,4 \%)$ & 1,87 & 0,906 \\
\hline Biologia-Diurno (CCS) & 120 & $50(41,7 \%)$ & $7(5,8 \%)$ & 2,73 & 1,154 \\
\hline Biologia-Licenciatura. Noturna (CCS) & 40 & $2(5,0 \%)$ & $0(0,0 \%)$ & 1,57 & 0,559 \\
\hline Biologia-Modalidade médica (CCS) & 30 & $16(53,3 \%)$ & $1(3,3 \%)$ & 2,87 & 1,204 \\
\hline Engenharia Civil(CT) & 120 & $100(83,3 \%)$ & $32(16,7 \%)$ & 4,12 & 1,192 \\
\hline Engenharia Eletrônica (CT) & 80 & $78(97,5 \%)$ & $59(73,8 \%)$ & 6,03 & 1,669 \\
\hline Engenharia Eletrotécnica (CT) & 60 & $54(90,0 \%)$ & $22(36,7 \%)$ & 4,29 & 1,219 \\
\hline Engenharia Mecânica (CT) & 100 & $98(98,0 \%)$ & $49(49,0 \%)$ & 5,01 & 1,292 \\
\hline Engenharia Metalúrgica (CT) & 50 & $36(72,0 \%)$ & $7(14,0 \%)$ & 3,67 & 1,176 \\
\hline Engenharia Naval (CT) & 70 & $52(74,3 \%)$ & $11(15,7 \%)$ & 3,72 & 1,386 \\
\hline Engenharia Produção (CT) & 80 & $80(100 \%)$ & $61(76,3 \%)$ & 5,65 & 1,346 \\
\hline Total da Escola de Engenharia & 560 & $498(88,9 \%)$ & $241(43,0 \%)$ & 4,70 & \\
\hline Engenharia Química (CT) & 240 & $145(60,4 \%)$ & $49(20,4 \%)$ & 3,50 & 1,608 \\
\hline Matemática Atuária (CCMN) & 20 & $16(80,0 \%)$ & $5(25,0 \%)$ & 3,84 & 1,489 \\
\hline Matemática Estatística (CCMN) & 20 & $14(70,0 \%)$ & $3(15,0 \%)$ & 3,56 & 1,157 \\
\hline Matemática Informática (CCMN) & 120 & $107(89,2 \%)$ & $63(52,5 \%)$ & 4,98 & 1586 \\
\hline Matemática Licenc. Noturna (CCMN) & 60 & $18(30,0 \%)$ & $1(1,7 \%)$ & 2,26 & 0,955 \\
\hline Matemática Curso Diurno (CCMN) & 60 & $38(63,3 \%)$ & $8(13,3 \%)$ & 3,34 & 1,351 \\
\hline Meteorologia (CCMN) & 21 & $2(9,5 \%)$ & $0(0,0 \%)$ & 1,85 & 0,687 \\
\hline Química Licenc. Noturna (CCMN) & 40 & $4(10,0 \%)$ & $0(0,0 \%)$ & 1,65 & 0,640 \\
\hline Química Curso Diurno (CCMN) & 50 & $17(34,0 \%)$ & $5(10,0 \%)$ & 2,49 & 1,488 \\
\hline Geologia (CCMN) & 50 & $8(16,0 \%)$ & $1(2,0 \%)$ & 1,88 & 1,124 \\
\hline Astronomia (CCMN) & 15 & $5(33,3 \%)$ & $1(6,7 \%)$ & 2,45 & 1,526 \\
\hline Física Curso Diurno (CCMN) & 120 & $56(46,7 \%)$ & $14(11,7 \%)$ & 2,94 & 1,429 \\
\hline Física Licenc.Noturna (CCMN) & 40 & $11(27,5 \%)$ & $1(2,5 \%)$ & 2,41 & 1,059 \\
\hline Pedagogia $(\mathrm{CFCH})^{*}$ & 28 & $6(21,4 \%)$ & $1(3,6 \%)$ & 2,36 & 1,208 \\
\hline
\end{tabular}




\section{Tabela III}

Resultados da prova de Física do vestibular para candidatos classificados no ano de 1996: número total de classificados, números com notas $\geq 3$ e 5, média e desvio-padrão das notas.

\begin{tabular}{|c|c|c|c|c|c|}
\hline Curso & Total & Com nota $\geq 3$ & Com nota $\geq 5$ & Média & Desvio padrão \\
\hline grupos $1+2+3$ & 3.088 & $1464(47,4 \%)$ & $594(19,2 \%)$ & 2,90 & 2,052 \\
\hline Arquitetura (CLA) & 240 & $72(30,0 \%)$ & $17(7,1 \%)$ & 2,33 & 1,431 \\
\hline Desenho Industrial Prog.Visual (CLA) & 50 & $24(48,0 \%)$ & $4(8,0 \%)$ & 2,97 & 1,304 \\
\hline Desenho Industrial Proj. Prod. (CLA) & 50 & $15(30,0 \%)$ & $3(6,0 \%)$ & 2,39 & 1,502 \\
\hline Medicina $(\mathrm{CCS})$ & 192 & $191(99,5 \%)$ & $165(85,9 \%)$ & 6,15 & 1,240 \\
\hline Odontologia(CCS) & 80 & $73(91,3 \%)$ & $39(48,8 \%)$ & 4,89 & 1,661 \\
\hline Microbiologia(CCS) & 35 & $8(22,9 \%)$ & $1(2,9 \%)$ & 2,14 & 1,261 \\
\hline Farmácia (CCS) & 144 & $42(29,2 \%)$ & $7(4,9 \%)$ & 2,29 & 1,277 \\
\hline Nutrição(CCS) & 72 & $13(18,1 \%)$ & $2(2,8 \%)$ & 2,05 & 1,060 \\
\hline Biologia-Diurno (CCS) & 120 & $47(39,12 \%)$ & $10(8,3 \%)$ & 2,66 & 1,426 \\
\hline Biologia-Licenciatura. Noturna (CCS) & 40 & $1(2,5 \%)$ & $1(2,5 \%)$ & 0,81 & 0,919 \\
\hline Biologia-Modalidade médica (CCS) & 30 & $10(33,3 \%)$ & $2(6,7 \%)$ & 2,46 & 1,570 \\
\hline Engenharia Civil(CT) & 120 & $95(79,2 \%)$ & $32(16,7 \%)$ & 4,00 & 1,432 \\
\hline Engenharia Eletrônica (CT) & 80 & $79(98,8 \%)$ & $57(71,3 \%)$ & 5,78 & 1,536 \\
\hline Engenharia Eletrotécnica (CT) & 60 & $50(83,3 \%)$ & $23(38,3 \%)$ & 4,26 & 1,403 \\
\hline Engenharia Mecânica (CT) & 100 & $91(91,0 \%)$ & $36(36,0 \%)$ & 4,47 & 1,430 \\
\hline Engenharia Metalúrgica (CT) & 50 & $27(54,0 \%)$ & $3(6,0 \%)$ & 3,07 & 1,229 \\
\hline Engenharia Naval (CT) & 70 & $43(61,4 \%)$ & $7(10,0 \%)$ & 3,23 & 1,243 \\
\hline Engenharia Produção (CT) & 80 & $80(100,0 \%)$ & $66(82,5 \%)$ & 5,93 & 1,196 \\
\hline Total da Escola de Engenharia & 560 & $465(83,0 \%)$ & $224(40 \%)$ & 4,46 & \\
\hline Engenharia Química (CT) & 230 & $123(53,5 \%)$ & $34(14,8 \%)$ & 3,17 & 1,621 \\
\hline Matemática Atuária (CCMN) & 20 & $14(70,0 \%)$ & $3(15,0 \%)$ & 3,66 & 1,446 \\
\hline Matemática Estatística (CCMN) & 20 & $15(75,0 \%)$ & $1(5,0 \%)$ & 3,54 & 0,615 \\
\hline Matemática Informática (CCMN) & 120 & $108(90,0 \%)$ & $59(49,2 \%)$ & 4,96 & 1592 \\
\hline Matemática Licenc. Noturna (CCMN) & 60 & $20(33,3 \%)$ & $3(5,0 \%)$ & 2,49 & 1,386 \\
\hline Matemática Curso Diurno (CCMN) & 60 & $34(56,7 \%)$ & $4(6,7 \%)$ & 3,14 & 1,272 \\
\hline Meteorologia (CCMN) & 13 & $0(0,0 \%)$ & $0(0,0 \%)$ & 1,24 & 0,784 \\
\hline Química Licenc. Noturna (CCMN) & 40 & $6(15,0 \%)$ & $1(2,5 \%)$ & 1,60 & 1,121 \\
\hline Química Curso Diurno (CCMN) & 50 & $9(18,0 \%)$ & $2(4,0 \%)$ & 1,71 & 1,214 \\
\hline Geologia (CCMN) & 33 & $3(9,1 \%)$ & $0(0,0 \%)$ & 1,38 & 0,851 \\
\hline Astronomia (CCMN) & 15 & $1(6,7 \%)$ & $0(0,0 \%)$ & 1,91 & 0,880 \\
\hline Física Curso Diurno (CCMN) & 120 & $22(18,3 \%)$ & $6(5,0 \%)$ & 2,01 & 1,557 \\
\hline $\begin{array}{c}\text { Física Licenc.Noturna (CCMN) } \\
\text { Pedagogia }(\mathrm{CFCH})^{*}\end{array}$ & 40 & $5(12,5 \%)$ & $1(2,5 \%)$ & 1,53 & 1,229 \\
\hline
\end{tabular}




\section{Tabela IV}

Resultados da prova de Física do vestibular para candidatos classificados no ano de 1997:

Número total de classificados, números com notas $\geq 3$ e 5 , média e desvio-padrão das notas.

\begin{tabular}{|c|c|c|c|c|c|}
\hline Curso & Total & Com nota $\geq 3$ & Com nota $\geq 5$ & Média & Desvio padrão \\
\hline grupos $1+2+3$ & 2963 & $2048(69,2 \%)$ & $1144(38,6 \%)$ & 4,20 & 2,100 \\
\hline grupo 1 (biomédico: CCS) & 1.317 & $744(56,5 \%)$ & $380(28,8 \%)$ & 3,67 & 2,264 \\
\hline grupo 2 (técnico-científico: $\mathrm{CT}+\mathrm{CCMN}$ ) & 1.254 & $1055(84,1 \%)$ & $677(54,0 \%)$ & 4,99 & 1,990 \\
\hline grupo 3 (técnico-humano: CLA) & 392 & $249(63,5 \%)$ & $87(22,2 \%)$ & 3,49 & 1,758 \\
\hline Arquitetura (CLA) & 240 & $168(70,0 \%)$ & $58(24,2 \%)$ & 3,78 & 1,602 \\
\hline Desenho Industrial Prog.Visual (CLA) & 50 & $43(86,0 \%)$ & $21(42,0 \%)$ & 4,57 & 1,289 \\
\hline $\begin{array}{c}\text { Desenho Industrial Proj.Prod. (CLA) } \\
\text { Medicina (CCS) }\end{array}$ & 50 & $35(70,0 \%)$ & $8(16,0 \%)$ & 3,56 & 1,3523 \\
\hline Odontologia(CCS) & 80 & $80(100,0 \%)$ & $75(93,8 \%)$ & 6,46 & 1,060 \\
\hline Microbiologia(CCS) & 35 & $30(85,7 \%)$ & $15(42,9 \%)$ & 4,24 & 1,596 \\
\hline Farmácia (CCS) & 144 & $97(67,4 \%)$ & $25(17,4 \%)$ & 3,44 & 1,425 \\
\hline Nutrição(CCS) & 72 & $40(55,5 \%)$ & $2(2,8 \%)$ & 2,92 & 1,014 \\
\hline Biologia-Diurno (CCS) & 120 & $86(71,7 \%)$ & $29(24,2 \%)$ & 3,80 & 1,471 \\
\hline Biologia-Licenciatura. Noturna (CCS) & 40 & $7(17,5 \%)$ & $0(0,0 \%)$ & 1,86 & 1,118 \\
\hline Biologia-Modalidade médica (CCS) & 30 & $23(76,7 \%)$ & $5(16,7 \%)$ & 3,85 & 1,516 \\
\hline Engenharia Civil(CT) & 120 & $119(99,2 \%)$ & $93(77,5 \%)$ & 5,81 & 1,275 \\
\hline Engenharia Eletrônica (CT) & 80 & $80(100,0 \%)$ & $78(97,5 \%)$ & 7,26 & 1,159 \\
\hline Engenharia Eletrotécnica (CT) & 60 & $60(100,0 \%)$ & $54(90,0 \%)$ & 6,14 & 0,883 \\
\hline Engenharia Mecânica (CT) & 100 & $99(99,0 \%)$ & $91(91,0 \%)$ & 6,24 & 1,204 \\
\hline Engenharia Metalúrgica (CT) & 50 & $50(100,0 \%)$ & $30(60,0 \%)$ & 5,20 & 1,189 \\
\hline Engenharia Naval (CT) & 70 & $64(91,4 \%)$ & $29(41,4 \%)$ & 4,60 & 1,333 \\
\hline Engenharia Produção (CT) & 80 & $80(100 \%)$ & $80(100 \%)$ & 7,37 & 0,924 \\
\hline Total da Escola de Engenharia & 560 & $552(98,6 \%)$ & $455(81,2 \%)$ & 6,15 & \\
\hline Engenharia Química (CT) & 230 & $164(71,3 \%)$ & $61(26,5 \%)$ & 3,84 & 1,653 \\
\hline Matemática Atuária (CCMN) & 20 & $19(95,0 \%)$ & $8(40,0 \%)$ & 4,70 & 1,027 \\
\hline Matemática Estatística (CCMN) & 20 & $19(95,0 \%)$ & $8(40,0 \%)$ & 4,39 & 1,060 \\
\hline Matemática Informática (CCMN) & 120 & $119(99,2 \%)$ & $101(84,2 \%)$ & 5,95 & 1,349 \\
\hline Matemática Licenc. Noturna (CCMN) & 60 & $32(53,3 \%)$ & $5(8,3 \%)$ & 3,02 & 1,362 \\
\hline Matemática Curso Diurno (CCMN) & 60 & $54(90,0 \%)$ & $20(33,3 \%)$ & 4,54 & 1,364 \\
\hline Meteorologia (CCMN) & 9 & $1(11,1 \%)$ & $0(0,0 \%)$ & 2,29 & 0,884 \\
\hline Química Licenc. Noturna (CCMN) & 24 & $6(25,0 \%)$ & $0(0,0 \%)$ & 1,89 & 1,097 \\
\hline Química Curso Diurno (CCMN) & 37 & $15(40,5 \%)$ & $5(13,5 \%)$ & 2,78 & 1,801 \\
\hline Geologia (CCMN) & 14 & $6(42,9 \%)$ & $2(14,3 \%)$ & 2,88 & 2,005 \\
\hline Astronomia (CCMN) & 20 & $16(80,0 \%)$ & $7(35,0 \%)$ & 4,16 & 1,873 \\
\hline Física Curso Diurno (CCMN) & 67 & $43(64,2 \%)$ & $18(26,9 \%)$ & 3,85 & 2,042 \\
\hline Física Licenc.Noturna (CCMN) & 13 & $9(69,2 \%)$ & $0(0,0 \%)$ & 3,01 & 0,846 \\
\hline Pedagogia $(\mathrm{CFCH})^{*}$ & 90 & $16(16,7 \%)$ & $4(4,4 \%)$ & 1,61 & 1,412 \\
\hline
\end{tabular}




\section{Física Aplicada para Desenho Industrial}

\section{Programa}

1) Origens da Física. Relacionamento da Física com outras ciências e com as técnicas.

2) Mecânica de partícula. Conceitos de massa, força, velocidade, aceleração, velocidade angular, momento angular, torque, estabilidade, atrito, energia, trabalho e momento de inércia. Equilíbrio de um corpo.

3) Mecânica dos fluidos. Conceitos de densidade, pressão e viscosidade. Regimes de fluxo de um fluido. Movimento harmônico. Ondas mecânicas e sonoras.

4) Som. Mecanismo de audição. Intensidade e freqüência. Mecânica de movimentos amortecidos e o isolamento acústico.

5) Luz. Fontes luminosas. Intensidade, comprimento de onda e freqüência. Mecanismos da visão diurna e da noturna. Reflexão e refração. Fosforescência e fluorescência. Materiais bons e maus refletores. Lentes. Máquina fotográfica. Distância mínima para a visão. Fenômenos ondulatórios da luz: difração (em redes, na pupila e em filmes) e interferência. Tamanho mínimo de um objeto visível. Holografia. Fibras óticas.

6) Eletricidade. Corrente elétrica e voltagem. Lei de Ohm. Efeito Joule. Magnetismo. Eletroímãs. Materiais isolantes, condutores e supercondutores.

7) Calor. Produção e dissipação. Temperatura e calor específico. Propriedades térmicas dos materiais. Medição da temperatura.

8) Átomos e moléculas. Sólidos. Radiações. Danos causados em sólidos pela luz solar e por outras radiações. Métodos físicos de alteração de superfícies.

\section{Ementa}

Origens da Física. Mecânica de partícula e de corpo rígido. Mecânica dos fluidos. Movimentos oscilatórios e ondas. Som: produção e recepção. Luz: produção e recepção. Reflexão e refração. Mecanismos da visão. Lentes. Fenômenos ondulatórios da luz. Propriedades óticas de materiais. Eletricidade e magnetismo. Corrente e potencial elétricos. Propriedades elétricas de materiais. Calor: produção e propagação. Temperatura e propriedades térmicas de materiais. Átomos e moléculas. Sólidos. Radiações. Laser.

\section{Física para Ciências Biológicas (Farmácia e Biologia)}

\section{Programa Analítico}

1) Movimento: descrição e causas

1.1) Um pouco de matemática: o conceito de derivada

1.2) Posição, velocidade, aceleração e momento linear

1.3) Forças, trabalho, potência e energia

1.4) Movimento circular: centrífugas, satélites e espectrômetros de massa

1.5) Leis de conservação: energia, momento linear e momento angular

2) Movimentos oscilatórios e ondas

2.1) Movimento harmônico simples

2.2) Energia de vibração

2.3) Ondas

2.4) Som e audição

2.5) Ondas eletromagnéticas 
3) Átomos, moléculas, núcleos e radiações

3.1)Espectro de emissão de átomos; experiências que indicam não ser a luz uma onda nem os elétrons partículas

3.2)O modelo de Bohr para o átomo de hidrogênio; o elétron como onda

3.3)A estrutura em camadas dos átomos

3.4)Ligações entre átomos e estrutura molecular

3.5)Radiações alfa, beta, gama e X

3.6)Um pouco mais de matemática: crescimento e decaimento exponenciais, as equações de Lotka-Volterra

3.7)Radioatividade e decaimento radioativo; datação usando raios gama

3.8) Atividade, dose e dose equivalente

3.9)Radiobiologia e radioproteção

4) Emissão e absorção de luz por átomos e moléculas

4.1)Fontes de luz

4.2)Lei de Beer-Lambert para a absorção de luz

4.3)Rotação molecular

4.4) Vibração molecular

4.5)Transições eletrônicas em moléculas

4.6)Moléculas atmosféricas, luz e vida na Terra

4.7)Raios X e determinação da composição química de amostras

5) Eletricidade

5.1)Corrente e voltagem

5.2)Elementos usados em circuitos

5.3)Exemplos de circuitos

5.4)Propriedades elétricas passivas de axônios e membranas celulares

6) Instrumentação

6.1)Medidas de correntes e de voltagens

6.2)Medidas térmicas

6.3)Amplificação e filtragem dos valores medidos

6.4) Visualização das grandezas medidas

7) Luz, lentes e microscópios

7.1)Reflexão e refração

7.2)Formação de imagens por superfícies e lentes

7.3)Formação de imagens no olho humano

7.4)Interferência de luz

7.5)Difração; tamanho mínimo de um objeto visível

7.6)Microscópios óticos e eletrônicos

7.7)Luz polarizada

8) Calor, temperatura e superfícies

8.1)Temperatura, calor e movimento molecular

8.2) Calor específico

8.3)Calores latentes de fusão e de evaporação

8.4)Transmissão de calor:condução, convecção e radiação

8.5)Produção e dissipação de calor no corpo humano

9) Propriedades mecânicas de superfícies, de sólidos e de líquidos

9.1)Energia superficial e tensão superficial

9.2)Ângulo de contato e molhabilidade

9.3) Capilaridade

9.4)Hidroestática, pressão e empuxo

9.5)Tração, alongamento e módulos elásticos

9.6)Energia elástica armazenada

9.7)Fluxos laminar e viscoso de um fluido; equação de Bernoulli 